\title{
Soldagem por Difusão de Aços Inoxidáveis para Fabricação de Trocadores de Calor Compactos
}

\author{
Marcus Vinícius Volponi Mortean ${ }^{1}$, Augusto José de Almeida Buschinelli2 ${ }^{2}$ Kleber Vieira de Paiva ${ }^{3}$, \\ Marcia Barbosa Henriques Mantelli ${ }^{1}$, Josef Remmel ${ }^{4}$ \\ 1 Universidade Federal de Santa Catarina - UFSC, Departamento de Engenharia Mecânica, Florianópolis, SC, Brasil. \\ 2 Universidade Federal do Rio Grande do Norte - UFRN, Departamento de Engenharia de Materiais, Natal, RN, Brasil. \\ 3 Universidade Federal de Santa Catarina - UFSC, Centro de Engenharias da Mobilidade, Joinville, SC, Brasil. \\ 4 Forschungszentrum Jülich, Departamento de Técnicas de Soldagem e Materiais, Jülich, Alemanha.
}

Recebido: 17 Fev., 2016

Aceito: 22 Mar., 2016

E-mails: mortean@labtucal.ufsc.br (MVVM), buschinelli@ct.ufrn.br (AJAB)
Resumo: A união de materiais diferentes ou componentes com geometrias complexas muitas vezes requer processos de uniões especiais, como por exemplo, uma fonte de energia de alta densidade como laser ou feixe de elétrons para soldagem por fusão ou mesmo um processo de soldagem no estado sólido. Em particular, este trabalho descreve os experimentos recentes da aplicação da soldagem por difusão no estado sólido (SDES) para diferentes tipos de aços inoxidáveis: austenítico AISI 316L, duplex UNS 31803 e superduplex UNS 327250. A soldagem por difusão foi realizada sob alto vácuo a $1050{ }^{\circ} \mathrm{C}$, durante 60 minutos, empregando uma pressão uniaxial de 18-35 MPa. A qualidade da união foi avaliada por microscopia óptica e testes mecânicos. Os resultados preliminares indicam a necessidade de otimização dos parâmetros de processo para os aços duplex e superduplex. Os resultados positivos alcançados no presente trabalho permitiram a fabricação de protótipos de trocadores de calor compacto em aço inoxidável, utilizando o novo método de fabricação, desenvolvido por LABTUCAL / UFSC, através do qual o processo de corte a jato de água é aplicado para confeccionar com precisão os canais do núcleo do permutador de calor.

Palavras-chave: Soldagem por difusão no estado sólido; Aço inoxidável; Trocador de calor compacto.

\section{Diffusion Welding of Stainless Steels for Fabrication of Compact Heat Exchangers}

Abstract: The joining of dissimilar materials or components with particular geometry often requires special union procedures, for instance a high density energy source as laser or electron beam for fusion welding or even necessarily a solid state welding process. In particular, this work describes the recent experience on applying the solid-state diffusion bonding (SSDB) to different types of stainless steels: austenitic AISI 316L, duplex UNS 31803 and superduplex UNS 327250. The SSDB was realized under high vacuum at $1050{ }^{\circ} \mathrm{C}$ for $60 \mathrm{~min}$, employing uniaxial hydrostatic pressure of 18-35 MPa. The quality of the joints was evaluated by optical microscopy and mechanical tests. The preliminary results indicate the necessity of optimization of the process parameters for the duplex and superduplex steels. The positive results of the present study allowed the fabrication of compact heat exchanger prototype in stainless steel, employing the new manufacturing method, developed by LABTUCAL/UFSC, whereby a water jet is applied to precisely cut the channels of the heat exchanger core.

Key-words: Solid-state diffusion bonding; Stainless steel; Compact heat exchanger.

\section{Introdução}

Por se tratar de processo de união no estado sólido, em que não apenas está ausente a zona fundida junto à interface de ligação, o que previne ou minimiza a degradação de microestruturas funcionais, mas também onde não ocorre deformação plástica macroscópica da estrutura, a soldagem por difusão tem sido explorada há mais de meio século para a fabricação de componentes com áreas extensas de união, para componentes pré-usinados e com geometrias complexas, bem como para junção de metais dissimilares [1,2]. A aplicação do processo em campos estratégicos como o nuclear prossegue até os dias atuais, como atestam trabalhos recentes focados na fabricação de reatores rápidos ou componentes da primeira parede de centrais a fusão. Também é extensa a atividade voltada para fabricação
Este é um artigo publicado em acesso aberto (Open Access)
sob a licenca Creative Commons Attribution Non-Commercia que permite uso, distribuicão e reprodução em qualquer meio, sem restriçōes desde que sem fins comerciais e que trabalho original seja corretamente citado. 
de trocadores de calor compactos e tubos de calor, visando aplicações na indústria química, petroquímica, e até mesmo em aeronaves [2-6].

Na soldagem por difusão as superfícies a serem unidas são mantidas em íntimo contato a uma temperatura sempre abaixo da temperatura solidus de qualquer dos componentes da junta. Assim a união ocorre como resultado da difusão no estado sólido e deformação macroscópica não é essencial para o processo. Entretanto o conceito de soldagem por difusão abrange o caso da eventual formação de fase líquida, oriunda da interdifusão de elementos de materiais dissimilares, ou entre esses e uma fina lâmina usada como intercamada, que deve ajustar a transição de propriedades entre metais muito distintos.

De acordo com Lison [7] a soldagem por difusão é classificada como um processo topoquímico lento, termo que enfatiza a elevada exigência imposta na preparação prévia das superfícies a serem unidas: essas devem ter um acabamento polido $(\mathrm{Ra}<0,4 \mu \mathrm{m})$ e o processo de soldagem precisa ser realizado em uma atmosfera que não permita a formação de camadas superficiais na área de união.

Trabalha-se com baixas pressões de compressão, sob uma temperatura dentro da faixa de recristalização dos materiais a serem unidos: usualmente entre 0,53 e 0,88 da temperatura solidus daquele com menor temperatura de fusão. $O$ processo de união propriamente dito ocorre após atingida a temperatura de soldagem e ser aplicada pressão. Inicialmente, com a pressão aplicada, ocorre por mecanismo de fluência o aplainamento de picos de rugosidade e o consequente rompimento de eventuais camadas superficiais, o que conduz a um aumento da área de contato. Com isso são ativadas forças metálicas de ligação entre elementos de sistemas cristalinos não mais independentes. Após a obtenção da ligação metálica ainda é introduzida energia, o que conduz a trocas de átomos entre os parceiros de união através da superfície de ligação. Como resultado das trocas atômicas na região da interface original, no caso das uniões entre materiais similares, são formados novos grãos que não podem ser mais associados a nenhum dos parceiros originais isoladamente [7].

A Figura 1, extraída de Bouquet et al. [8], representa a evolução da interface de união durante a SDES, definido em três etapas. Na primeira, a deformação plástica localizada resulta em colapso da aspereza superficial, com aumento da área de contato real, Figura 1a. Na sequência o preenchimento dos vazios remanescentes prossegue via mecanismos controlados por difusão, tais como fluência e difusão em contornos de grãos, Figura $1 \mathrm{~b}$. Conforme os autores a união estaria finalmente completa pela "movimentação interfacial de contornos de grãos" (Interfacial Grain Boundary Motion), Figura 1c, que admite-se seria apenas uma designação mais específica e moderna para a clássica "recristalização" mencionada acima por Lison [7].
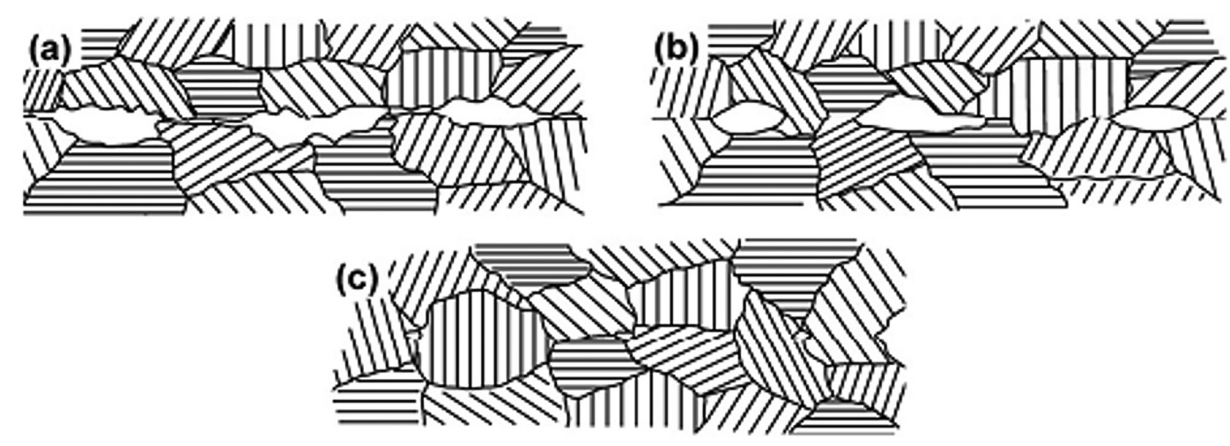

Figura 1. Mecanismos de formação da interface na soldagem por difusão: (a) deformação plástica localizada, colapso da aspereza superficial e aumento da área de contato real; (b) preenchimento de vazios remanescentes via mecanismo de fluência e difusão em contornos de grãos; e (c) união final por "movimentação interfacial de contornos de grãos" [8].

Segundo Paiva [9] a soldagem por difusão é um processo de união empregado quando requisitos estruturais são importantes, em virtude principalmente da excelente resistência mecânica obtida nas regiões de ligação. Além disso, esta técnica possibilita a soldagem de peças metálicas de grande porte, sem que precisem receber um preaquecimento. Como desvantagem, destacam-se a elevada duração do ciclo térmico, a produção através de pequenos lotes e as limitações na geometria de união [10-12]. 
De acordo com Bucklow [13] os principais parâmetros envolvidos no processo são tempo (t), temperatura $(T)$ e pressão (P), sendo a temperatura normalmente a variável determinante e as demais variáveis ajustadas em sua função. Na prática a discussão fica centrada sobretudo no tempo, para valores fixos das outras duas variáveis T e $\mathrm{P}$, adotando-se usualmente a máxima pressão tolerável em termos de evitar uma deformação plástica macroscópica durante a união. Os processos de difusão e fluência operantes durante a união por difusão seguem a lei da velocidade (V) de Ahrenius, conforme Equações 1 e 2:

$$
V=A \exp \left(\frac{-Q}{R T}\right)
$$

ou

$$
\ln V=\ln A-\left(\frac{Q}{R T}\right)
$$

onde $\mathrm{A}$ é a velocidade máxima (i.e. quando $\mathrm{T}=\infty$ ), $\mathrm{Q}$ é a energia de ativação, $\mathrm{T}$ é a temperatura em $\mathrm{K}$ e $\mathrm{R}$ é a constante dos gases perfeitos. A lei de Ahrenius demonstra que uma mudança em T deve ser compensada por variação logarítmica de pressão ou tempo. Na prática um bom ponto de referência para a temperatura é 0,7 do ponto de fusão. A Figura 2a apresenta uma visão geral do campo de temperaturas adequadas, bem como da superposição, para os processos de soldagem por pressão e por difusão. A Figura $2 b$, por outro lado, proporciona uma visão mais específica da faixa dos parâmetros de soldagem por difusão para vários aços [13].
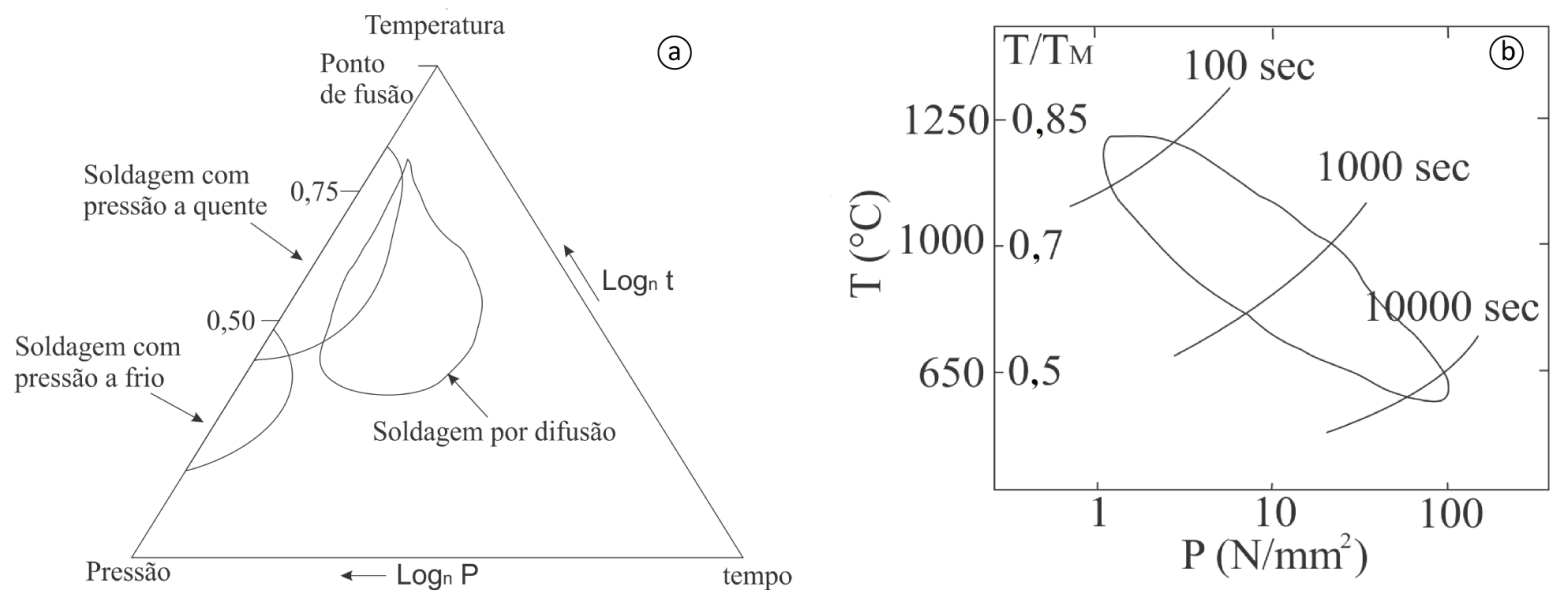

Figura 2. a) Parâmetros de soldagem por difusão e pressão, indicando zonas de superposição; e b) parâmetros de soldagem por difusão para vários aços [13].

A soldagem por difusão de aços inoxidáveis com materiais dissimilares foi estudada em diversos trabalhos, encontrando-se todavia um número menor de publicações sobre a união de aços inoxidáveis austeníticos entre si [14]. A Tabela 1 exibe um resumo dos parâmetros de ligação explorados por alguns autores na soldagem por difusão dos aços inoxidáveis austeníticos AISI 304 e 316L.

Verifica-se que os conjuntos de parâmetros citados como mais adequados são bastante distintos, o que a priori seria admissível, uma vez que T, t e P são nesse caso variáveis interligadas: uma elevação da T poderia ser compensada por redução do t ou da P, ou seja, os 3 parâmetros de soldagem são em princípio escolhidos livremente [7].

No presente trabalho, em se tratando de ensaios preliminares, optou-se por aplicar o mesmo ciclo térmico (temperatura e tempo) e também nível de pressão similar tanto ao aço inoxidável austenítico AISI 316L, material selecionado para a construção do trocador de calor, como para os possíveis candidatos: duplex UNS 31803 e super duplex UNS 32750. 
Tabela 1. Resumo dos parâmetros de soldagem.

\begin{tabular}{lccccc}
\hline \multicolumn{1}{c}{ Autor } & Material & Tempo $(\mathbf{m i n})$ & Temp. $\left({ }^{\circ} \mathbf{C}\right)$ & Pressão $(\mathrm{MPa})$ & $\begin{array}{c}\text { Melhor soldagem } \\
\text { Pavlova [15] }\end{array}$ \\
\hline 304 & 30,40 e 60 & 850,1000 e 1100 & $12-17$ & $40 / 60 \mathrm{~min}, 1000{ }^{\circ} \mathrm{Ce} 17 \mathrm{MPa}$ \\
An e Tu [14] & $316 \mathrm{~L}$ & 60,120 e 180 & $850,950,1050$ e 1100 & 10 & $120 \mathrm{~min}, 1100^{\circ} \mathrm{Ce} 10 \mathrm{MPa}$ \\
Li et al. [5] & $316 \mathrm{~L}$ & 180 & 1100 & 10 & $180 \mathrm{~min}, 1100{ }^{\circ} \mathrm{Ce} 10 \mathrm{MPa}$ \\
\hline
\end{tabular}

\section{Materiais e Métodos}

\subsection{Metais de base, metalografia e ensaio de cisalhamento}

Foi realizada a soldagem do aço inoxidável austenítico AISI 316L e dos aços inoxidáveis duplex UNS 31803 e super duplex UNS 32750, cujas composições nominais aparecem na Tabela 2.

Tabela 2. Composição nominal dos aços inoxidáveis.

\begin{tabular}{lcccccccccc}
\hline & $\mathbf{C}_{\max }$ & $\mathbf{N}$ & $\mathbf{C r}$ & $\mathbf{N i}$ & $\mathbf{M o}$ & $\mathbf{M n}_{\max }$ & $\mathbf{S i}$ & $\mathbf{P}_{\max }$ & $\mathbf{S}_{\max }$ & $\mathbf{C u}_{\max }$ \\
AISI 316L & 0,03 & 0,11 & $16,5-18,5$ & $10-13$ & $2,0-2,5$ & 2,0 & 1,0 & 0,045 & 0,030 & - \\
UNS 31803 & 0,03 & $0,10-0,22$ & $21-23$ & $4,5-6,5$ & $2,5-3,5$ & 2,0 & 1.0 & 0,035 & 0,015 & - \\
UNS 32750 & 0,03 & $0,24-0,35$ & $25-26$ & $6-8$ & $3-4,5$ & 2,0 & $0,8-1,0$ & 0,035 & 0,015 & 0,50 \\
\hline
\end{tabular}

Os corpos de prova soldados, a partir de chapas de $2 \mathrm{~mm}$ de espessura, permitiram extração de duas peças para ensaio mecânico de cisalhamento e uma para análise metalográfica, conforme indicado esquematicamente na Figura 3. Para análise metalográfica os corpos de prova foram lixados com papel de carbeto de silício até a granulometría 1000 e polidos com pasta de diamante até 0,25 $\mu \mathrm{m}$. A microestrutura foi revelada com o reagente V2-A (200 ml H2O destilada / $200 \mathrm{ml} \mathrm{HCl} \mathrm{(37 \% )} \mathrm{/} 20$ ml HNO3 (65\%) / 0,6 ml de reagente de Vogel) e observada sob aumento de até 500 vezes.

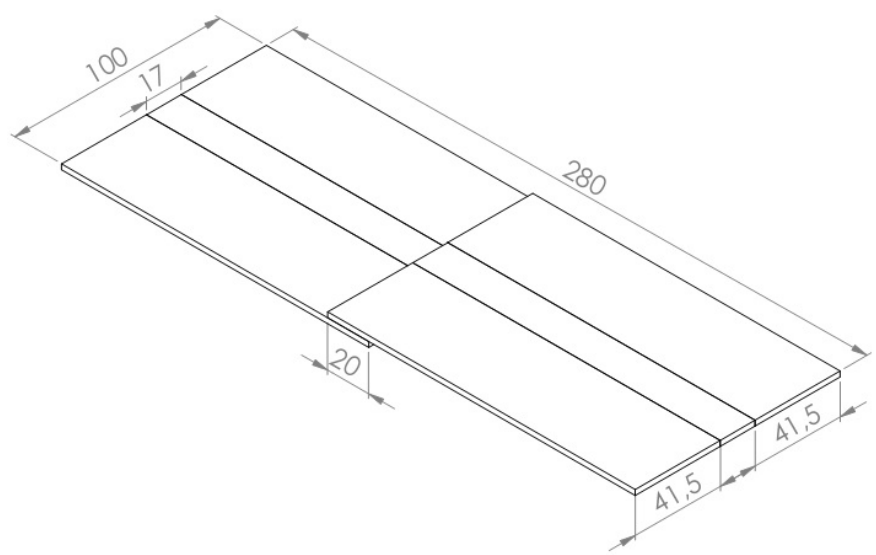

Figura 3. Dimensões do corpo de prova para o teste de cisalhamento.

\subsection{Procedimentos de soldagem}

Os procedimentos de soldagem por difusão empregados neste trabalho foram realizados no Centro de Pesquisas de Jülich (Forschungszentrum Jülich) na Alemanha. Para os testes foi utilizado forno de alto vácuo específico para soldagem por difusão, o qual é composto por um impulsionador hidráulico que realiza a prensagem da matriz sobre as amostras, garantindo assim uma melhor distribuição da pressão e um maior paralelismo entre as matrizes. Além de aplicar a pressão de uma forma homogênea, este equipamento ainda pode trabalhar com elevadas temperaturas, em um grande período de tempo, em atmosfera controlada a vácuo. 
A Figura 4 apresenta o forno de soldagem por difusão empregado no presente estudo. A câmara de soldagem apresenta uma base de $300 \times 300 \mathrm{~mm}$ e altura de $300 \mathrm{~mm}$. As forças máxima e mínima que os pistões conseguem aplicar são 1500 e $7,5 \mathrm{kN}$, respectivamente, e a máxima temperatura de trabalho é de $1400^{\circ} \mathrm{C}$. Contudo, deve-se tomar cuidado extra quando se trabalha com a máxima força, pois neste caso a máxima temperatura permitida é de apenas $1000^{\circ} \mathrm{C}$. $\mathrm{O}$ equipamento é capaz de atingir vácuo de aproximadamente 10-6 mbar.

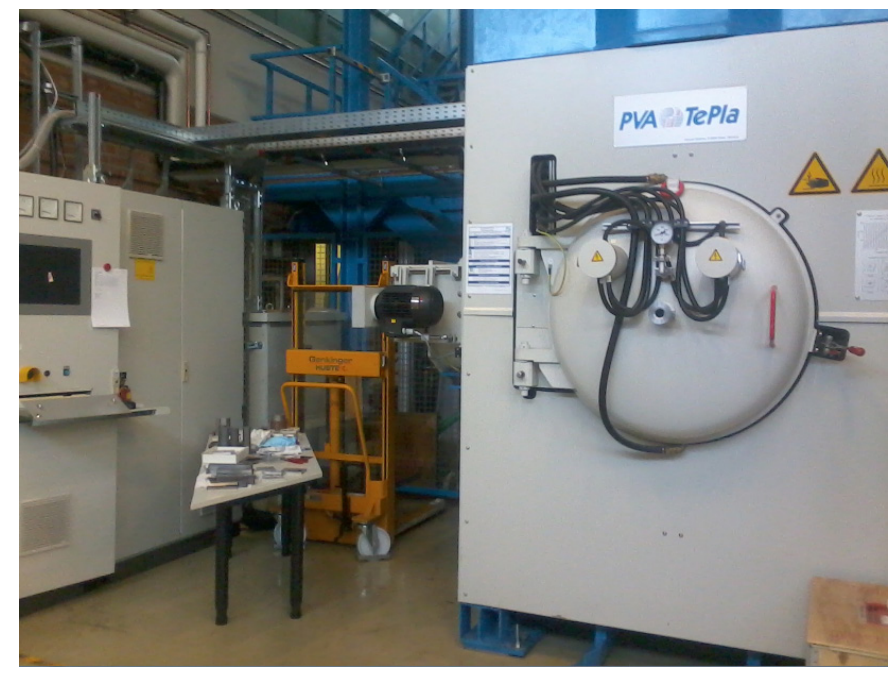

Figura 4. Forno de soldagem por difusão do Centro de Pesquisas de Jülich.

Primeiramente, para a limpeza superficial das amostras foi empregado um banho ultrassônico em álcool durante 10 minutos. A partir desse momento, para evitar contaminações futuras, o manuseio ocorreu sempre com luvas cirúrgicas.

Para garantir a integridade física do forno foram utilizadas placas de TZM (principal liga refratária de Mo, contendo $0.5 \% \mathrm{Ti} \mathrm{e} 0.08 \% \mathrm{Zr}$ ), inseridas entre a prensa e a amostra (Figura 5), recebendo essas uma fina camada de alumina. As placas de TZM e a camada de alumina são responsáveis por evitar o contato direto da prensa com a peça a ser soldada, visando proteger a matriz do forno e impedir a indesejada soldagem entre tais componentes. Finalizando o procedimento de preparação, o conjunto era inserido no interior do forno para a soldagem.

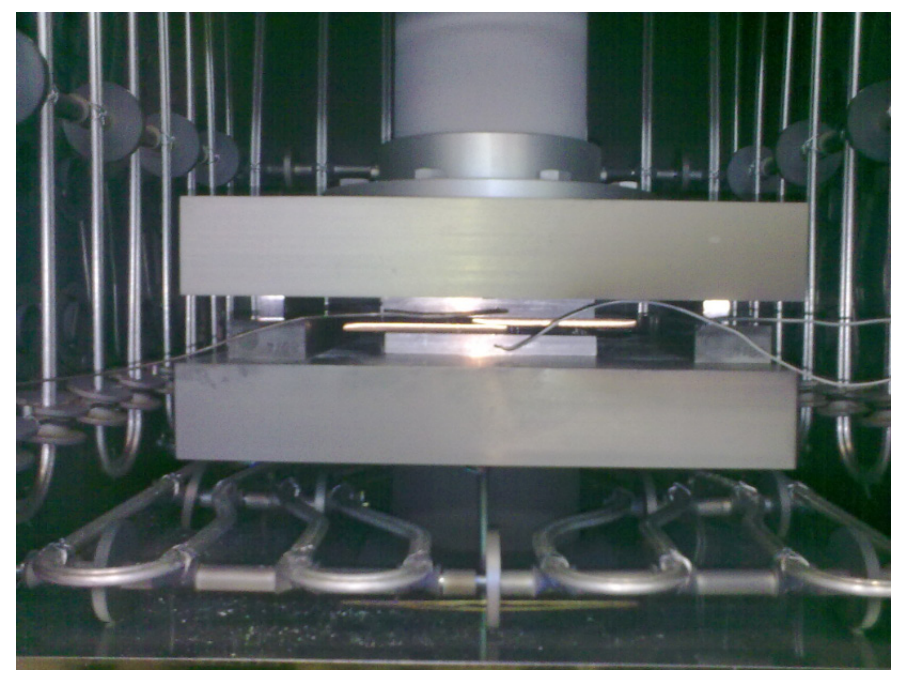

Figura 5. Conjunto composto por prensa, placas de TZM e amostra a ser soldada. 


\subsection{Parâmetros de soldagem}

O aço inoxidável $316 \mathrm{~L}$ foi soldado sob um mesmo ciclo térmico, apresentado a seguir, porém sob duas pressões diferentes (18 e $35 \mathrm{MPa})$ :

- Rampa 1: $20^{\circ} \mathrm{C}$ até $900^{\circ} \mathrm{C} \rightarrow 7,5^{\circ} \mathrm{C} / \mathrm{min}$

- Patamar 1: $900{ }^{\circ} \mathrm{C} \rightarrow 60 \mathrm{~min}$

- Rampa 2: $900^{\circ} \mathrm{C}$ até $1050^{\circ} \mathrm{C} \rightarrow 2,5^{\circ} \mathrm{C} / \mathrm{min}$

- Patamar 2: $1050^{\circ} \mathrm{C} \rightarrow 60 \mathrm{~min}$

Os aços duplex e superduplex foram soldados com ciclo térmico similar, porém sob pressão de $30 \mathrm{MPa}$ :

- Rampa 1: $20^{\circ} \mathrm{C}$ até $900^{\circ} \mathrm{C} \rightarrow 7,5^{\circ} \mathrm{C} / \mathrm{min}$

- Patamar 1: $900{ }^{\circ} \mathrm{C} \rightarrow 120 \mathrm{~min}$

- Rampa 2: $900^{\circ} \mathrm{C}$ até $1050^{\circ} \mathrm{C} \rightarrow 1,25^{\circ} \mathrm{C} / \mathrm{min}$

- Patamar 2: $1050{ }^{\circ} \mathrm{C} \rightarrow 60 \mathrm{~min}$

- Pressão constante durante todo o ciclo $30 \mathrm{MPa}$

Em todos os casos o vácuo no interior da câmara permaneceu entre $10^{-4}$ e $10^{-6} \mathrm{mbar}$.

\section{Resultados e Discussão}

\subsection{Análise metalográfica}

As fotos da Figura 6 mostram vista de topo das juntas soldadas, com linhas delimitando posição de corte para retirada dos corpos de prova para o ensaio mecânico e análise metalográfica. A Figura 7 apresenta a vista lateral dos corpos de prova na seguinte sequência: $316 \mathrm{~L}$ (soldado com $35 \mathrm{MPa}$ ), 316L (soldado com $18 \mathrm{MPa}$ ), super duplex UNS 32750 e duplex UNS 31803. Não se percebe qualquer indício de deformação para o aço inoxidável 316L, enquanto que as chapas dos aços duplex e superduplex sofreram acentuada macro-deformação plástica. O esmagamento das chapas na região de soldagem também já é perceptível nas vistas de topo das Figuras $6 \mathrm{~b}$ e $6 \mathrm{c}$. Essa é clara indicação de que os parâmetros temperatura e pressão devem ser reduzidos para os aços duplex e superduplex.

As Figuras 8 e 9 apresentam as interfaces de união do aço inoxidável 316L, conforme analisadas no microscópio ótico, para a soldagem sob as pressões de 18 e $35 \mathrm{MPa}$, respectivamente. Verifica-se a boa qualidade da união pela ausência de vazios ao longo da linha pouco definida da interface, através da qual pode-se, além disso, perceber a migração de contornos de grão através da interface pelo mecanismo citado por Bouquet et al. [8]. O defeito em forma de entalhe agudo nas Figuras 8 a e 9 a (regiões destacadas nas Figuras 7a e 7b, respectivamente) admite-se resultar da perda de planicidade (arredondamento) na borda da chapa, mostrando merecer especial cuidado a preparação prévia do material a ser soldado.

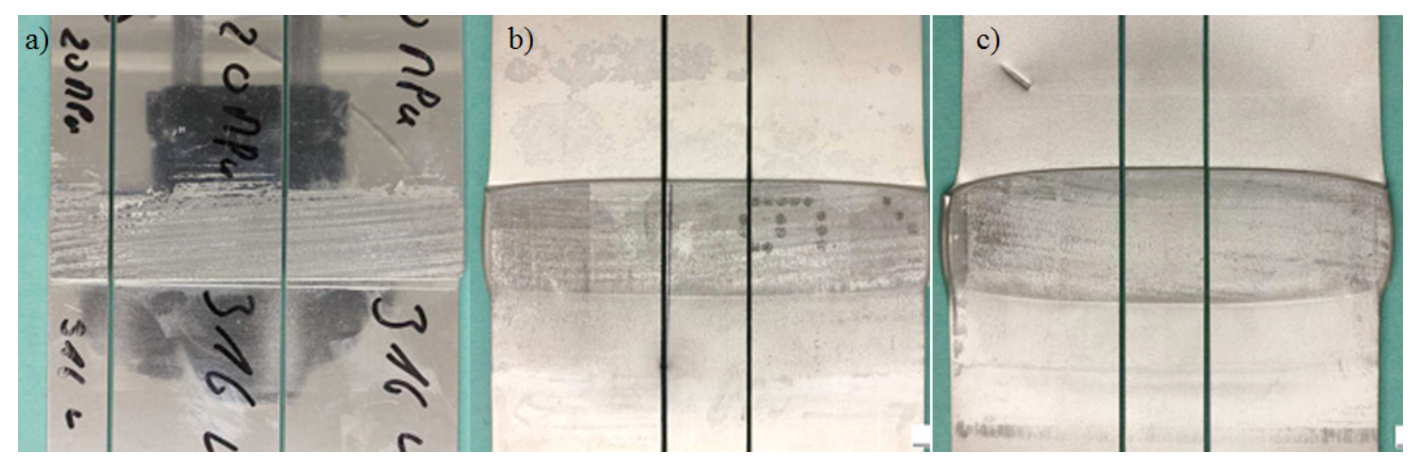

Figura 6. Resultado das amostras soldadas e esquema do plano de corte: (a) aço inoxidável 316L soldada com $18 \mathrm{MPa}$; (b) aço inoxidável super duplex UNS 32750; e (c) aço inoxidável duplex UNS 31803. 


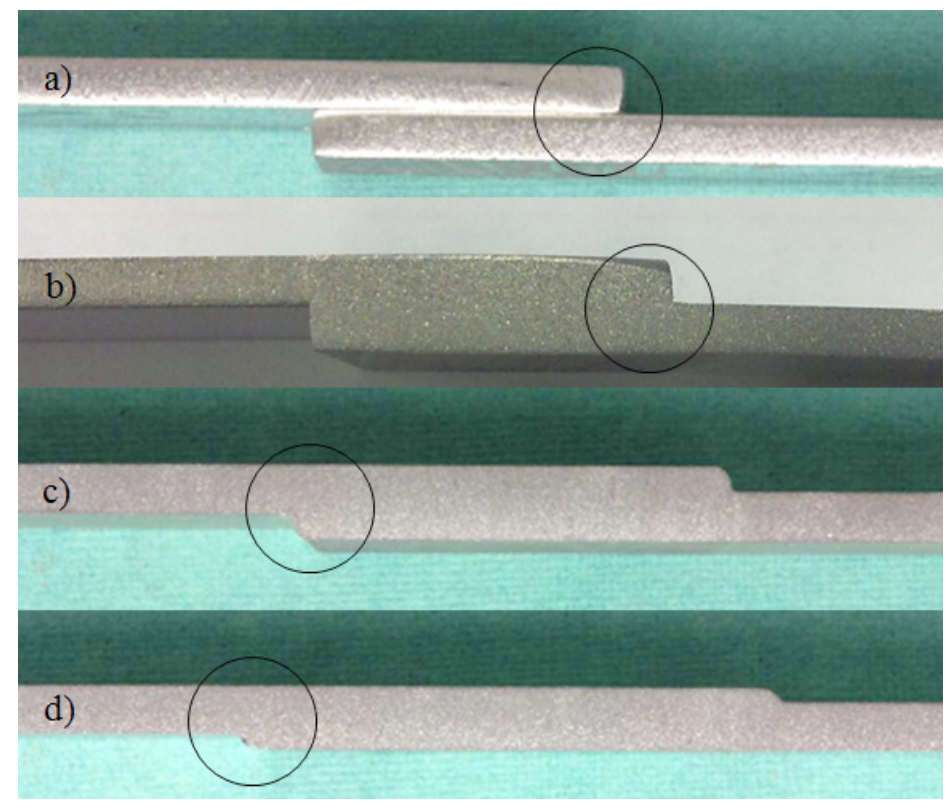

Figura 7. Vista lateral dos corpos de prova: (a) $316 \mathrm{~L}$ soldada com $18 \mathrm{MPa}$; (b) $316 \mathrm{~L}$ soldada com $35 \mathrm{MPa}$; (c) super duplex UNS 32750; e (d) duplex UNS 31803.
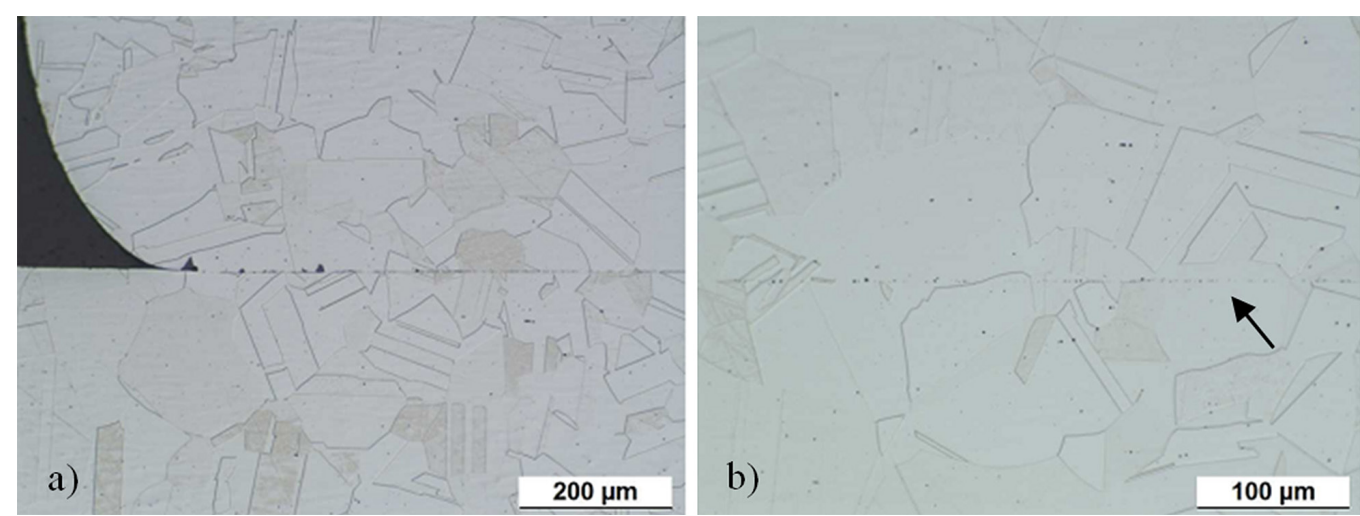

Figura 8. Microscopia ótica da união do aço inoxidável AISI 316L soldado sob 18MPa: (a) defeito em forma de entalhe resultante de perda de planicidade (arredondamento) na preparação da borda da chapa a ser soldada; e (b) detalhe mostrando boa qualidade da união, onde a seta indica migração de contornos de grão através da interface pelo mecanismo citado por Bouquet et al. [8].

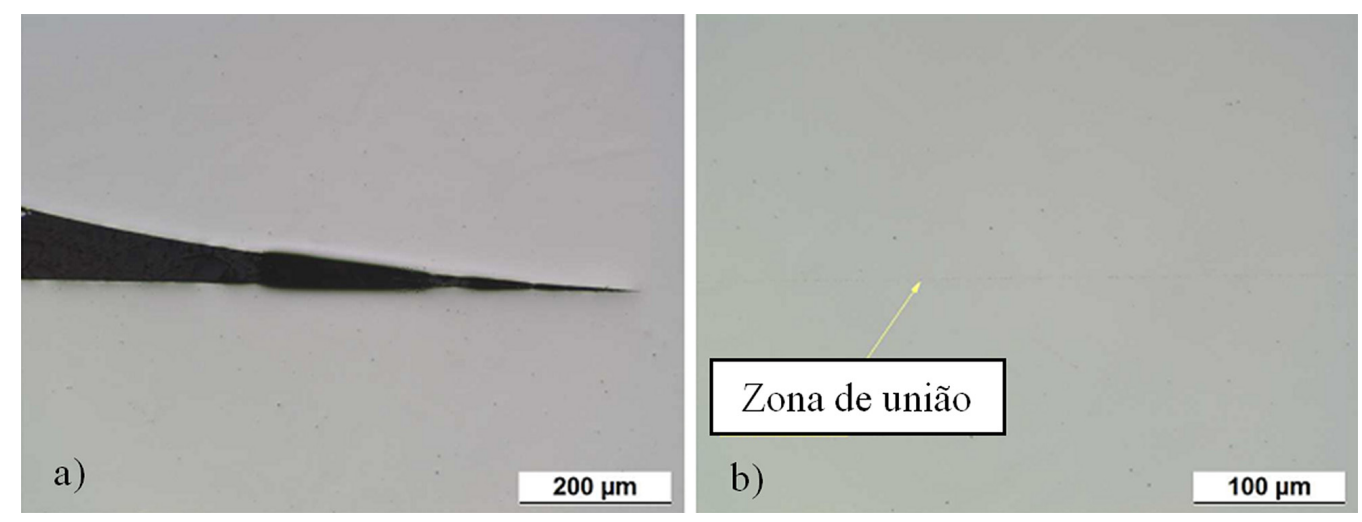

Figura 9. Microscopia ótica da união do aço inoxidável AISI 316L soldado sob 35MPa: (a) entalhe agudo resultante de perda de planicidade na preparação da chapa a ser soldada; e (b) boa qualidade da união pela ausência de vazios ao longo da linha pouco definida da interface. 
O resultado da metalografia dos aços inoxidáveis superduplex UNS 32750 e duplex UNS 31803, respectivamente nas Figuras 10 e 11, também apresenta uma união homogênea, não sendo possível identificar falhas ao longo da região de ligação entre as chapas.
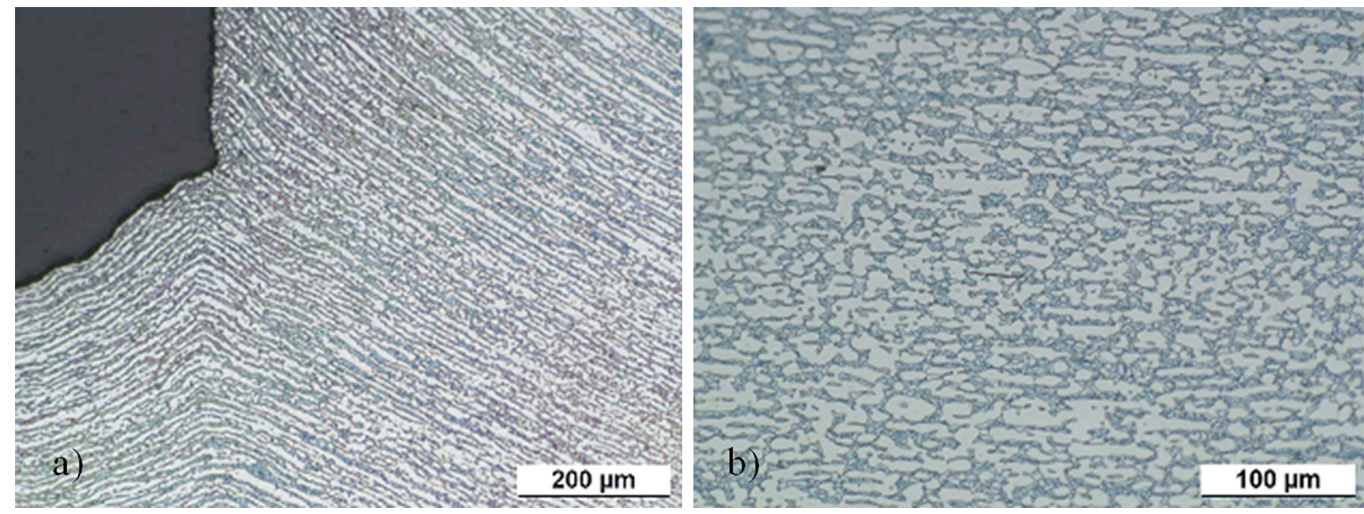

Figura 10. Microscopia ótica da zona de união do aço inoxidável super duplex UNS 32750: (a) microestrutura revelando acentuada macro-deformação plástica; e (b) detalhe da região de ligação mostrando união homogênea entre as chapas.
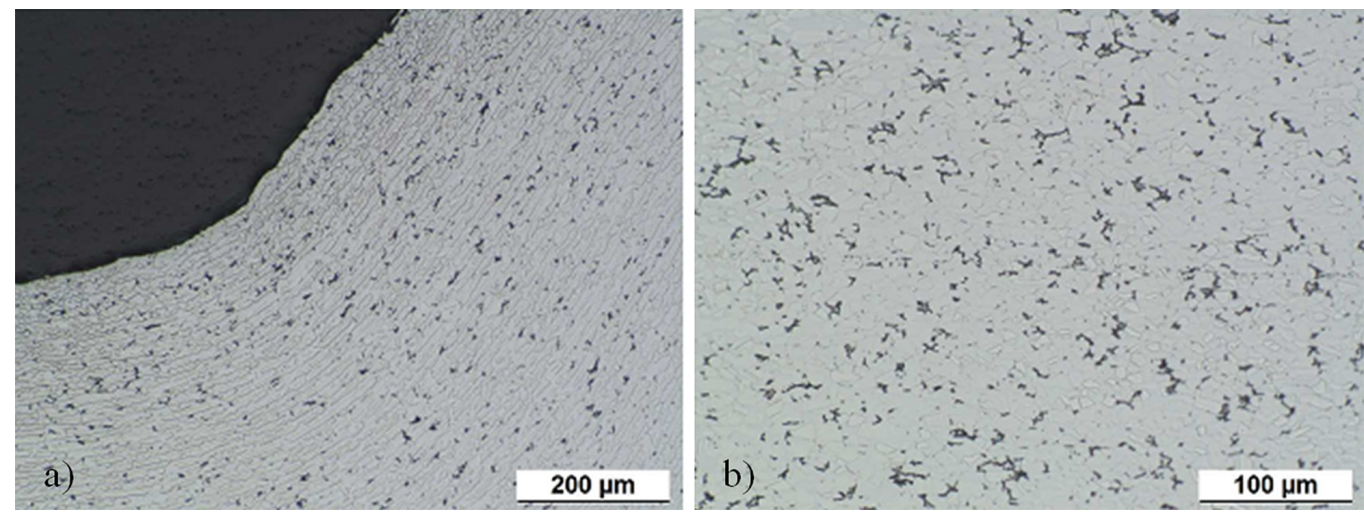

Figura 11. Microscopia ótica da zona de união do aço inoxidável duplex UNS 31803: (a) microestrutura da região de união mostrando macro-deformação plástica; e (b) detalhe destacando boa qualidade da soldagem pela ausência de vazios ao longo da imperceptível linha de união.

As Figuras 10a e 11a mostram a região de ligação destacada nas Figuras 7c e 7d, respectivamente. Constata-se como a pressão excessiva alterou a geometria do material, que originalmente apresentava um vértice próximo de $90^{\circ}$, mostrando que os parâmetros de soldagem empregados ( $1050^{\circ} \mathrm{C}$ e $30 \mathrm{MPa}$ ) devem ser corrigidos, para evitar deformação macroscópica acentuada. Isso se explicaria pela microestrutura duplex com fração elevada da fase ferrítica, onde a taxa de difusão é pelo menos 2 ordens de grandeza superior àquela no aço austenítico. Nesse contexto ainda é pertinente comentar que Yeh et al. [16] relatam ter obtido bom resultado soldando aço superduplex por procedimento em duas etapas sob T e P bastante inferiores $\left(880^{\circ} \mathrm{C} / 10 \mathrm{~min}\right.$ e $970{ }^{\circ} \mathrm{C} / 50 \mathrm{~min}$ e pressão de $7 \mathrm{MPa}$ ). Os autores destacam a possibilidade de aproveitar o efeito benéfico, para a qualidade da união no estado sólido, da deformação superplástica apresentada pelo aço com microestrutura refinada (6 7 $\mu \mathrm{m})$ sob temperaturas acima de $900{ }^{\circ} \mathrm{C}$.

\subsection{Resultados de ensaios de cisalhamento}

As imagens dos corpos de prova após o ensaio de cisalhamento são mostradas na Figura 12 e os resultados reunidos na Tabela 3. Em todos os testes a ruptura foi na região do metal base, comprovando a boa qualidade da junta soldada, livre de defeitos na zona da interface, conforme verificado no exame metalográfico. O maior valor de ruptura obtido para o aço duplex seria justificável pela inerente superior resistência dessa classe de aços frente aos inoxidáveis austeníticos. 

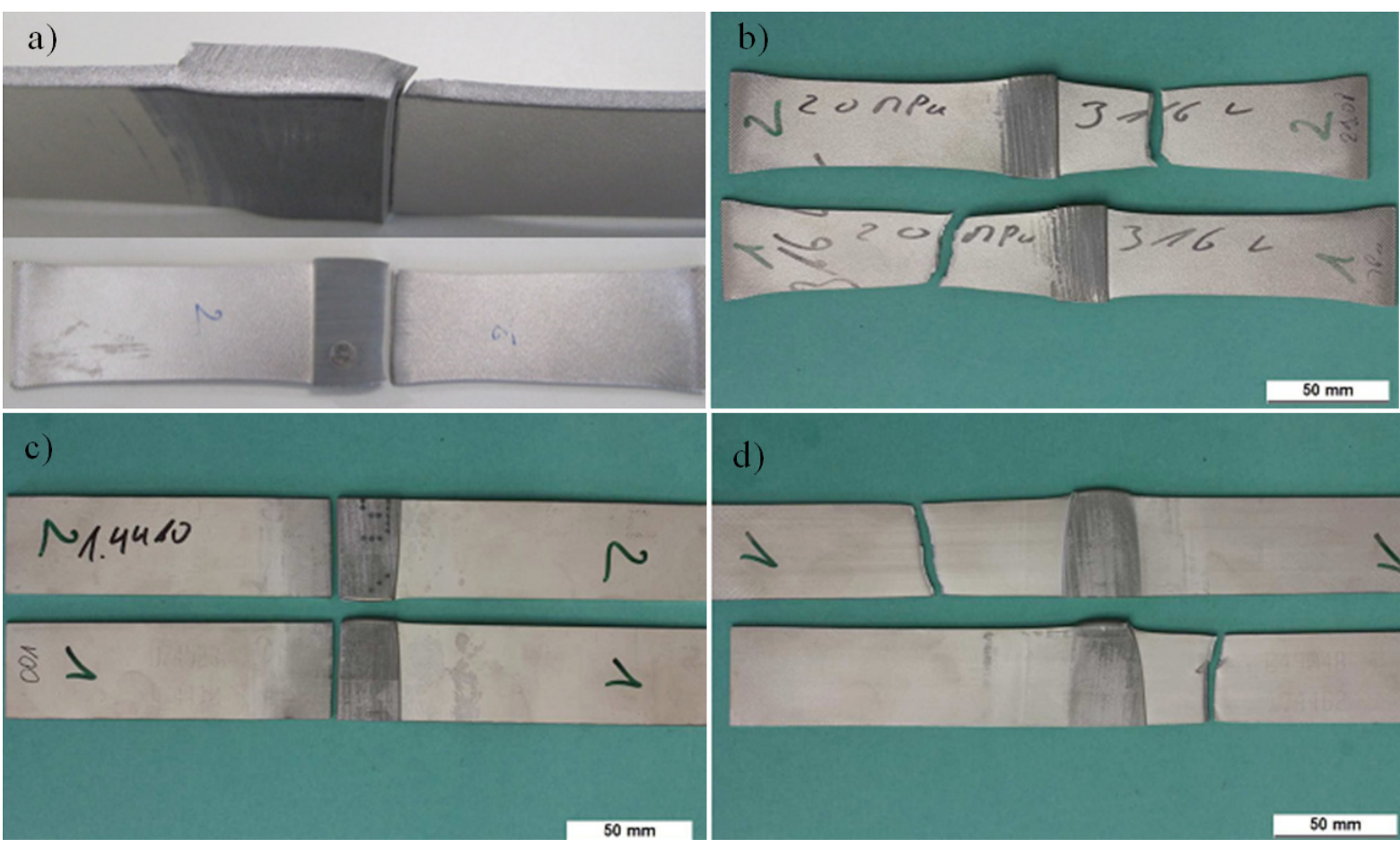

Figura 12. Ensaio mecânico: (a) 316L soldada com 35MPa; (b) 316L soldada com 18MPa; (c) UNS 32750; e (d) UNS 31803.

Tabela 3. Resultado do ensaio mecânico.

\begin{tabular}{lcccccccc}
\hline & \multicolumn{3}{c}{ Parâmetros de soldagem } & & \multicolumn{2}{c}{ Carga máxima (N) } & Local de \\
\cline { 2 - 3 } & $\mathbf{t}(\mathbf{m i n})$ & $\mathbf{T}\left({ }^{\circ} \mathbf{C}\right)$ & $\mathbf{P}(\mathbf{M P a})$ & & Amostra 1 & Amostra 2 & rompimento \\
Amostra 1 316L & 60 & 1050 & 35 & & 63262 & 66570 & Metal base \\
Amostra 2 316L & 60 & 1050 & 18 & & 69565 & 70091 & Metal base \\
Amostra 3 UNS 32750 & 60 & 1050 & 30 & & 58156 & 60145 & Metal base \\
Amostra 4 UNS 31803 & 60 & 1050 & 30 & & 95200 & 88877 & Metal base \\
\hline
\end{tabular}

Comparando as amostras de aço inoxidável AISI 316L, pode-se notar que ambos romperam na região do metal base, contudo o corpo de prova soldado com uma menor pressão teve uma resistência mecânica superior, e ainda apresentou uma deformação plástica mais acentuada, ocorrendo a formação de "pescoço".

\subsection{Soldagem por difusão de protótipo de trocador de calor em aço inox AISI 316L}

Apesar de ainda preliminares, os resultados positivos obtidos na SDES de corpos de prova em aço inoxidável austenítico AISI 316L, possibilitaram empregar os mesmos parâmetros (pressão $35 \mathrm{MPa}$ ) de soldagem para a fabricação de um protótipo do núcleo de um trocador de calor compacto, segundo projeto desenvolvido no Laboratório de Tubos de Calor (LABTUCAL) da Universidade Federal de Santa Catarina.

Trata-se de um inovador modelo de trocador de calor compacto tipo "pente" descrito no mestrado de Mortean [17] e objeto da patente PCT/BR2014/000408. A nova tecnologia emprega o processo de corte a jato de água para a fabricação de mini-canais em placas planas e o processo de soldagem por difusão para a confeç̧ão do núcleo do trocador. No trabalho pioneiro de Mortean [17] um protótipo foi soldado por difusão empregando o cobre C-12000 como metal base. Os resultados recentes da mesma tecnologia agora aplicada ao aço inoxidável são apresentados nas Figuras 13 a-d. 


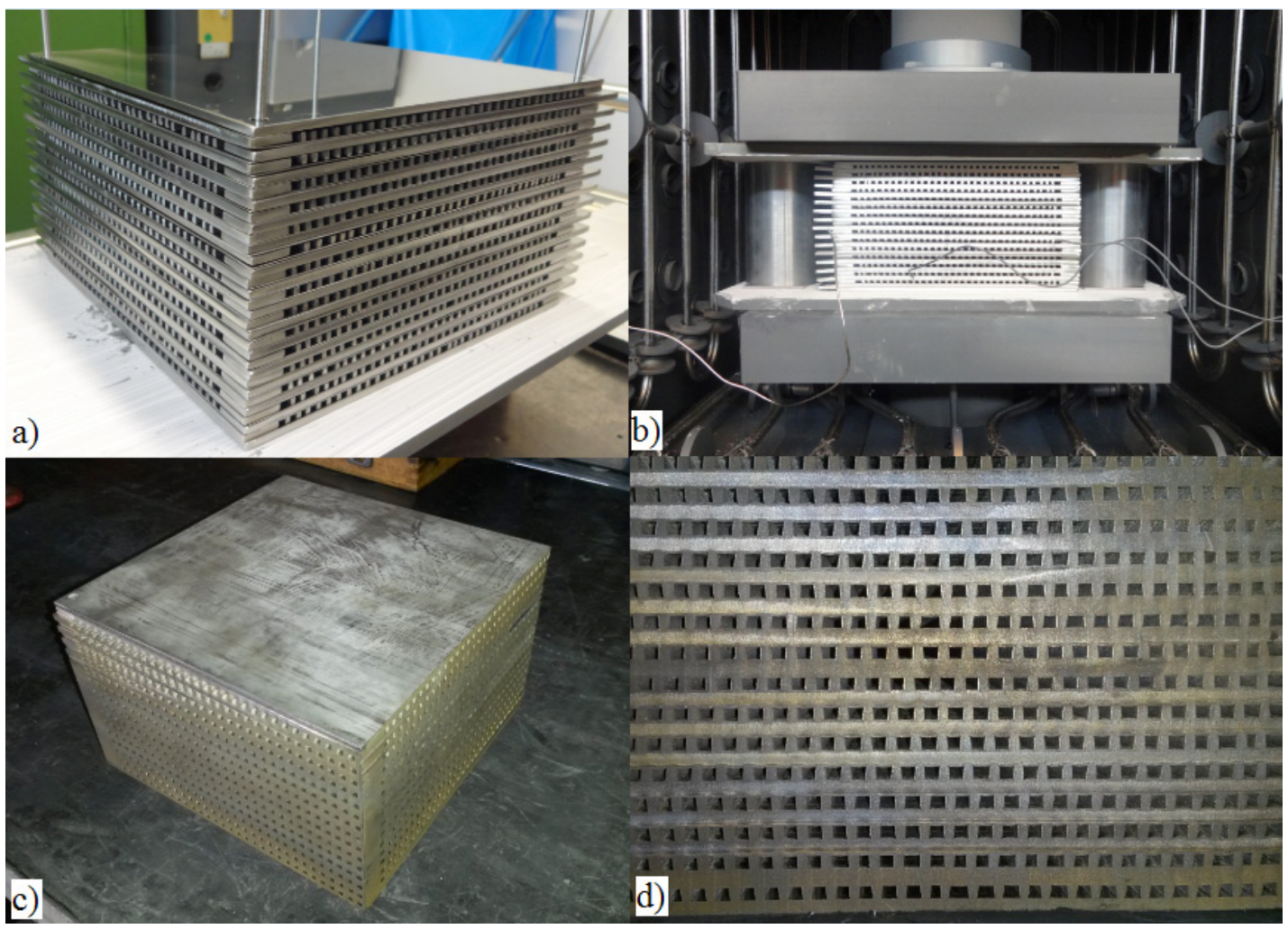

Figura 13. (a) Fase de empilhamento das camadas para formar o núcleo do trocador compacto; (b) vista do conjunto montado entre as placas do forno à vácuo; (c) núcleo soldado após o corte das extremidades em excesso; e (d) visão frontal mostrando detalhe dos canais quadrados no núcleo do trocador de calor.

Com base nos resultados apresentados propõe-se, como pesquisa futura, um estudo mais aprofundado dos parâmetros de soldagem por difusão do aço inoxidável 316L visando a aplicação em trocadores de calor compactos do tipo "pente", empregando para essa pesquisa o forno de soldagem por difusão existente no LABTUCAL, apresentado na Figura 14.

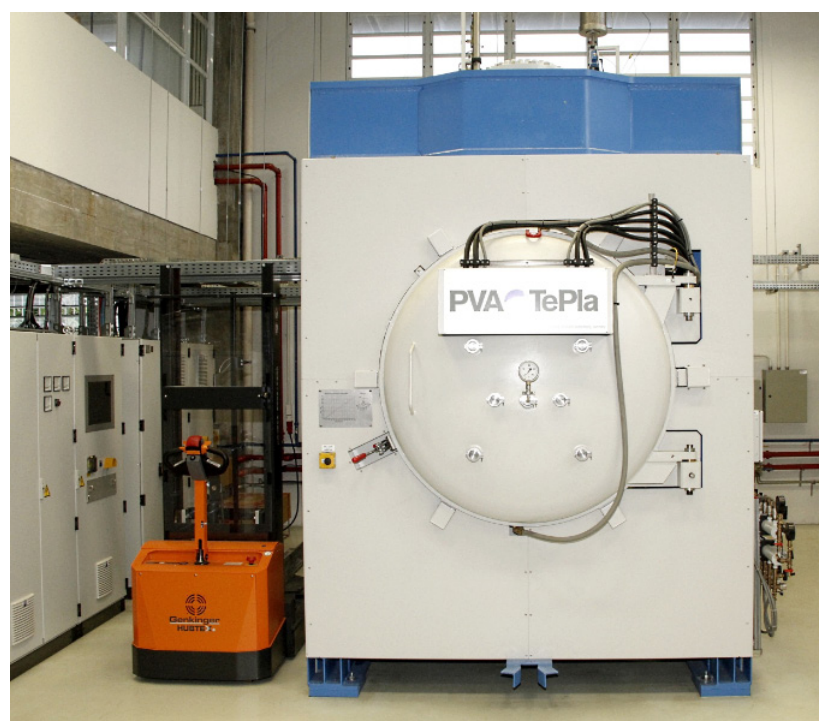

Figura 14. Forno de soldagem por difusão existente no Laboratório de Tubos de Calor (LABTUCAL) da Universidade Federal de Santa Catarina. 
O equipamento é capaz de controlar, de forma precisa, os quatro parâmetros fundamentais para o sucesso da soldagem por difusão: temperatura, pressão, atmosfera (inerte ou vácuo) e tempo. O forno conta com uma câmara de soldagem de $800 \mathrm{~mm}$ de largura, $600 \mathrm{~mm}$ de comprimento e $600 \mathrm{~mm}$ de altura, sendo capaz de aplicar cargas de até $2500 \mathrm{kN}$ e trabalhar com temperaturas de até $1700^{\circ} \mathrm{C}$. Na Tabela 4 são apresentadas algumas características técnicas do equipamento.

Tabela 4. Principais dados técnicos do forno de alto vácuo existente no LABTUCAL.

\begin{tabular}{lcc}
\hline \multicolumn{1}{c}{ Descrição Técnica } & Unidade & Valores \\
Máxima temperatura de operação & ${ }^{\circ} \mathrm{C}$ & 1700 \\
Homogeneidade de temperatura no forno vazio a $1000^{\circ} \mathrm{C}$ & ${ }^{\circ} \mathrm{C}$ & $\pm 4^{\circ} \mathrm{C}$ \\
Dimensões úteis & $\mathrm{mm}$ & $800 \times 600 \times 600$ \\
Máxima carga & $\mathrm{kN}$ & 2500 \\
Precisão da carga até $250 \mathrm{kN}$ & $\mathrm{kN}$ & $\pm 0,25$ \\
Precisão da carga até $2500 \mathrm{kN}$ & $\mathrm{kN}$ & $\pm 2,5$ \\
Nível de vácuo em forno vazio & $\mathrm{mbar}$ & $1 \times 10^{-6}$ \\
\hline
\end{tabular}

\section{Conclusões}

O aço inoxidável austenítico AISI 316L pode ser soldado com sucesso sob alto vácuo e pressão uniaxial de 18 e $35 \mathrm{MPa}$ na temperatura de $1050^{\circ} \mathrm{C}$ por $60 \mathrm{~min}$. Apesar de não haver indicação de macro-deformação plástica em corpos de prova, com objetivo de fabricar núcleos de trocador de calor com multicamadas de aço inoxidável, caberia um estudo sistemático para qualificar o processo numa faixa inferior de pressão.

A constatação de acentuada deformação plástica em corpos de prova de aços inoxidáveis duplex e superduplex indica que os parâmetros temperatura e pressão aplicados $\left(1050^{\circ} \mathrm{C}\right.$ e $\left.30 \mathrm{MPa}\right)$ são demasiados para esses materiais, o que se explicaria pela microestrutura com fração elevada da fase ferrítica, onde a taxa de difusão é pelo menos 2 ordens de grandeza superior àquela no aço austenítico.

Apesar de preliminares, os resultados positivos obtidos na SDES de corpos de prova em aço inoxidável austenítico permitiram a fabricação do núcleo de um inovador protótipo de trocador de calor compacto desenvolvido pelo LABTUCAL / UFSC.

\section{Referências}

[1] Schwartz MM. Modern metal joining techniques. New York: John Wiley \& Sons; 1969.

[2] Kasakow NF. Diffusionsschweißen in Vakuum. Moskau: Verlag Maschinenbau; 1968

[3] Noh S, Kasada R, Kimura A. Solid-state diffusion bonding of high-Cr ODS ferritic steel. Acta Materialia. 2011;59(8):31963204. http://dx.doi.org/10.1016/j.actamat.2011.01.059.

[4] Li SX, Xuan FZ, Tu ST. Fatigue damage of stainless steel diffusion bonded joints. Materials Science and Engineering. 2007;480(12):125-129. http://dx.doi.org/10.1016/j.msea.2007.06.062.

[5] Li SX, Li L, Yu S-R, Akid R, Xia H-B. Investigation of intergranular corrosion of $316 \mathrm{~L}$ stainless steel diffusion bonded joint by electrochemical potentiokinetic reactivation. Corrosion Science. 2011;53(1):99-104. http://dx.doi.org/10.1016/j.corsci.2010.09.027.

[6] Paiva KV, Mantelli MBH. Theoretical thermal study of wireplate mini heat pipes. International Journal of Heat and Mass Transfer. 2015;83:146-163. http://dx.doi.org/10.1016/j. ijheatmasstransfer.2014.11.049.

[7] Lison R. Wege zum Stoffschluss über Schweiss und Lötprozesse. Düsseldorf: DVS Verlag; 1998. (vol. 131).

[8] Bouquet N, Rigal E, Chomette S, Bernard F, Heintz O. Interface formation during HIP-bonding of austenitic stainless steel. Düsseldorf: DVS Berichte; 2013. (vol. 293).

[9] Paiva KV. Comportamento térmico em gravidade e micro gravidade de minitubos de calor do tipo fios-placas [dissertação de mestrado]. Florianópolis: Departamento de Engenharia Mecânica, Universidade Federal de Santa Catarina; 2007.

[10] Elssner G, Petzow G. Metal/ceramic joining. ISIJ International. 1990;30(12):1011-1032. http://dx.doi.org/10.2355/ isijinternational.30.1011.

[11] Martinelli AE. Diffusion bonding of silicon carbide and silicon nitride to molybdenum [tese de doutorado]. Montreal: Department of Mining and Metallurgical Engineering, Mcgill University; 1996. 228 p.

[12] American Welding Society. AWS Welding Handbook. 7th ed. Miami: The Macmillan Press; 1978.

[13] Bucklow IA. Diffusion bonding for product improvement and cost reduction. London: The Welding Institute; 1983. (Seminar Handbook). 
[14] An ZL, Tu ST. Mechanical performances and failure modes of direct diffusion bonding joints of $316 \mathrm{l}$ stainless steel. Key Engineering Materials. 2006;324-325:979-982. http://dx.doi. org/10.4028/www.scientific.net/KEM.324-325.979.

[15] Pavlova N. Aplicação do processo de soldagem por difusão na união de componentes inoxidáveis para uso espacial [dissertação de mestrado]. São José dos Campos: Instituto Tecnológico de Aeronáutica; 2005.
[16] Yeh MS, Tseng YH, Chuang TH. Effects of superplastic deformation on the diffusion welding of superdux 65 stainless steel. Welding Journal. 1999;78(9):301s-304s.

[17] Mortean MVV. Desenvolvimento de tecnologias de recheios para trocadores de calor compactos soldados por difusão [dissertação de mestrado]. Florianópolis: Departamento de Engenharia Mecânica, Universidade Federal de Santa Catarina; 2014 